\section{THU0373 USE OF CORTICOSTEROID HIP JOINT INJECTIONS IN SPONDYLOARTHRITIS PATIENTS UNDER TNF ALPHA INHIBITORS}

K. Maatallah ${ }^{1}$, A. Ben Ouhiba ${ }^{1}$, I. Mahmoud ${ }^{2}$, S. Belghali ${ }^{3}$, W. Hamdi ${ }^{1}$ M. Kchir ${ }^{1}$, R. Tekaya ${ }^{2}$, L. Abdelmoula ${ }^{2} .{ }^{1}$ Department of Rheumatology, M.T Kassab Institute; ${ }^{2}$ Department of Rheumatology, Charles Nicolle Hospital; ${ }^{3}$ Department of Rheumatology, Farhat Hached Hospital, Tunis, Tunisia

Background: The hip disease is a serious complication of spondyloarthritis $(\mathrm{SpA})$, engaging the functional prognosis of patients. TNF alpha inhibitors are a breakthrough for the treatment of SpA and the management of this complication. Objectives: To assess the efficacy of TNF alpha inhibitors on hip involvement in SpA by evaluating the use of intra-articular corticosteroid infiltrations.

Methods: Observational cohort study that included $94 \mathrm{SpA}$ patients with hip disease (ASAS2009). Two groups were studied. Group 1 (G1): patients under anti-TNF alpha therapy and Group 2 (G2): TNF alpha inhibitors naive patients. Clinical (BASDAI, BASFI, hip (pain/mobility), index of severity for osteoarthritis for the hip (ISH)), biological (CRP) data were assessed and the use of corticosteroid hip joint infiltration was compared. Evaluations were performed and compared between the 2 groups at baseline (T0), two years (T2) and Tn (greater than or equal to 3 years). The correlation study was made by Pearson test. A correlation was considered statistically significant if $p<0.05$.

Results: Group 1 and 2 included 48 and 46 patients respectively. The socio demographic and clinical characteristics of the disease were comparable between the two groups. Biological and radiological assessments of the two groups were comparable at T0. Group 1 had however a more active disease and a greater functional impairment. NSAIDs were prescribed in $40 \%$ of patients in $\mathrm{G} 1$ and $86 \%$ in $G 2(p<0.0001)$. DMARDS were prescribed in 20 patients in $G 1$ and in 22 patients in $\mathrm{G} 2(\mathrm{p}=0.6)$. In $\mathrm{G} 1$ patients received infliximab, adalimumab and etanercept in $48 \%, 15 \%$ and $37 \%$ of cases respectively. Four patients of G1 and three of G2 patients received intra-articular corticosteroid infiltration in the year prior to the initial assessment $(\mathrm{p}=0.7)$. Assessment at T2 showed a greater improvement in clinical and biological parameters of the disease in group 1 than in group 2 with $\Delta$ (T2-T0) significantly lower in group 1 for the BASDAI $(p<0.0001)$, the BASFI $(p<0.0001)$ and the ISH $(p=0.017)$. The number of painful hip was significantly lower in group $1(p<0.0001)$. The evaluation at Tn showed a sustained clinical and biological efficacy of TNF alpha inhibitors in Group 1. The use of corticosteroid injections was significantly higher in group 2. Table 1 summarizes the assessment of different parameters at T2 and Tn.

Conclusions: Hip involvement is a marker of severity of spondyloarthritis. AntiTNF alpha treatment is effective on hip disease. It reduces the use of intra articular injections of corticosteroids.

Disclosure of Interest: None declared

DOI: 10.1136/annrheumdis-2017-eular.6177

\section{THU0374 LONG-TERM EFFECTS OF TNF-ALPHA INHIBITORS ON BONE MINERAL DENSITY AND THE INCIDENCE OF VERTEBRAL FRACTURES IN PATIENTS WITH ANKYLOSING SPONDYLITIS}

K. Beek ${ }^{1}$, M. van der Weijden ${ }^{1}$, W. Lems ${ }^{1}$, C. van Denderen ${ }^{2}$, M. Nurmohamed ${ }^{1}$, I. van der Horst-Bruinsma ${ }^{1} .{ }^{1}$ Rheumatology, Amsterdam Rheumatology immunology Centre/VUmc and Reade; ${ }^{2}$ Rheumatology, Amsterdam Rheumatology immunology Centre/Reade, Amsterdam, Netherlands

Background: Ankylosing Spondylitis (AS) is not only characterized by pathological bone formation leading to ankylosis, but also by bone loss which may lead to vertebral fractures (VFx). TNF-alpha inhibitors (TNFi) have proven to be effective in blocking the inflammation process. A few studies also showed an increase of Bone Mineral Density (BMD) in AS patients treated with $\mathrm{TNFi}^{1-3}$ but the incidence of VFx after two years of treatment was increased. ${ }^{3-4}$

Objectives: To evaluate the long-term effect of TNFi on BMD and the incidence of VFx in patients with AS.

Methods: Consecutive TNFi naive patients diagnosed with AS according to the Modified New York criteria were included. Patients were recruited from the VUmc and the Amsterdam Outpatient clinic Reade and were treated with TNFi for 4 years. BMD at hip and lumbar spine (LS) were measured at baseline, after 2 and 4 years. T-scores were categorized as "normal BMD", "osteopenia" and "osteoporosis", based on the WHO osteoporosis criteria. ${ }^{5}$ The incidence of VFx was determined by two observers using the Genant method. ${ }^{6}$

Results: In total, 70 AS patients with complete datasets $(67.1 \%$ male) were included. The mean age was 41.6 years and the disease duration (time since diagnosis) was 9.8 years. At baseline $42 \%$ of the patients had a decreased BMD of the hip and $34 \%$ of the spine, of whom 19 patients (27\%) had both a decreased hip BMD as well as a decreased lumbar BMD. The BMD of spine and hip improved after 2 and 4 years of TNFi treatment (Table 1). In 7 patients (10\%), 8 VFx were observed both at baseline and after 2 years. After 4 years of TNFi-treatment 11 VFx were observed in 9 patients.

After 4 years, 2 out of 9 patients with $\geq 1$ VFx had a decreased BMD at hip and lumbar spine whereas the other 7 patients had a normal BMD. The majority of VFx was localized in the mid or lower thoracic spine.

Table 1, BMD measurement in spine and hip of 70 AS patients treated with TNFi

\begin{tabular}{lccc}
\hline & Baseline & After 2 years of TNFi & After 4 years of TNFi \\
\hline Osteopenia LS & $23(32.9)$ & $19(27.1)$ & $21(30.0)$ \\
Osteoporosis LS & $6(8.6)$ & $3(4.3)$ & $2(2.9)$ \\
Abnormal BMD LS & $29(41.5)$ & $21(31.4)$ & $23(32.9)$ \\
Osteopenia total hip & $22(31.4)$ & $19(27.1)$ & $16(22.9)$ \\
Osteoporosis total hip & $2(2.9)$ & $2(2.9)$ & $3(4.3)$ \\
Abnormal BMD total hip & $24(34.3)$ & $21(30.0)$ & $19(27.2)$ \\
Patients with VFx & $7(10.0)$ & $7(10.0)$ & $9(12.9)$ \\
Total number of VFx & 8 & 8 & 11 \\
\hline
\end{tabular}

*Lumbar Spine; ${ }^{* \star} \mathrm{N}=68$, because 2 patients had a total hip replacement. Abnormal BMD $=$ osteopenia and/or osteoporosis according to WHO guideline ${ }^{6}$. Vertebral fractures (VFx) are presented in number of patients with a VFx and the actual prevalence of VFx. Outcomes are presented in $\mathrm{n}(\%)$.

Conclusions: The percentage of relatively young AS patients with a decreased BMD at baseline of the hip and lumbar spine was high (34-41\%). After 4 years of TNFi-treatment the BMD of the lumbar spine improved in $8.6 \%$ of the patients and of the hip in $7.2 \%$ of the patients. At baseline, several vertebral fractures were found and a few additional vertebral fractures were observed after 4 years of treatment.

References:

[1] Visvanathan S et al. Ann Rheum Dis 2009

[2] Arends S et al. Arthritis Res Ther 2012.

[3] van der Weijden et al. J Reumatol 2016.

[4] Maas F et al. ClinExpRheumatol 2016

[5] Kanis JA et al. J Bone MinerRes 1994.

[6] Genant HK et al. J Bone MinerRes 1993.

Disclosure of Interest: None declared

DOI: 10.1136/annrheumdis-2017-eular.3398

\section{THU0375 CHARACTERISTICS ASSOCIATED WITH IMPROVEMENTS IN SPARCC SIJ AND ASDAS SCORES IN PATIENTS WITH NON-RADIOGRAPHIC AXIAL SPONDYLOARTHRITIS TREATED WITH ETANERCEPT}

K. de Vlam ${ }^{1}$, A. Burden ${ }^{2}$, M.A. Dilleen ${ }^{3}$, C. Boone ${ }^{4} .{ }^{1}$ Katholieke Universiteit, Leuven, Belgium; ${ }^{2}$ Quanticate, Hitchin; ${ }^{3}$ Pfizer, Sandwich, United Kingdom; ${ }^{4}$ Pfizer, SA/NV, Medical Department, Brussels, Belgium

Background: The EMBARK trial of etanercept (ETN) (NCT01258738) ${ }^{1}$ has demonstrated the long-term efficacy of ETN in patients with non-radiographic axial spondyloarthritis (nr-axSpA) and shown correlations between decreased inflammation and clinical outcomes. ${ }^{2}$

Objectives: To determine which baseline (BL) characteristics are associated with clinical improvements after 48 weeks of treatment with ETN in patients with nr-axSpA.

Methods: This post hoc analysis was performed on data from patients with nr-axSpA enrolled in the 92-week open-label phase of the EMBARK trial. The primary analysis population was the EMBARK modified intent-to-treat (mITT) population (patients who had $\geq 1$ dose of ETN, had $\geq 1$ on-therapy evaluation, and met the Assessment in Ankylosing Spondylitis classification criteria for axSpA). Patients' SpondyloArthritis Research Consortium of Canada (SPARCC) sacroiliac joint (SIJ) scores and Ankylosing Spondylitis Disease Activity Scores (ASDAS) were recorded, and patients were divided into 4 quadrants (Q1-4) based on the minimally important change (MIC) for each instrument (SPARCC SIJ score, change from $B L[c f b]$ of $\geq 2.5$; ASDAS, $c f b \geq 1.1$ ). Patients in Q1 achieved MIC in SPARCC SIJ but did not achieve MIC in ASDAS. Q2 did not achieve MIC in SPARCC SIJ and did not achieve MIC in ASDAS. Q3 did not achieve MIC in SPARCC SIJ but achieved MIC in ASDAS. Q4 achieved MIC in SPARCC SIJ and achieved MIC in ASDAS. Missing data were imputed using last observation carried forward. $P$-values were obtained using the Chi-squared test (categorical variables) and the Kruskal-Wallis test (continuous variables) in order to compare $\mathrm{BL}$ characteristics across improvement status. Multivariable

Abstract THU0373 - Table 1. Comparison of Clinical and biological variations between the 2groups at T2 and Tn

\begin{tabular}{|c|c|c|c|c|c|c|}
\hline & \multicolumn{3}{|c|}{ T2/T0 } & \multicolumn{3}{|c|}{$\mathrm{Tn} / \mathrm{T0}$} \\
\hline & G1 & G2 & $p$ & G1 & G2 & $p$ \\
\hline$\Delta \mathrm{ISH}$ & $-7,7[-19,2]$ & $-1,6[-19,8]$ & 0,01 & $-9,3[-20,2]$ & $0,1[-4,4]$ & 0,005 \\
\hline$\triangle B A S F I$ & $-2,7[-9,7]$ & $1,1[-1,4]$ & $<0,0001$ & $-3,2[-9,1]$ & $0,2[-3,6]$ & $<0,0001$ \\
\hline$\triangle \mathrm{BASDAI}$ & $-3[-8,3]$ & $0,4[-3,5]$ & $<0,0001$ & $-3,4[-9,2]$ & $-0,9[-6,4]$ & 0,001 \\
\hline Hip pain (\%) & 35 & 75 & $<0,0001$ & 20 & 67 & $<0,0001$ \\
\hline Limitation of hip mobility (\%) & 71 & 83 & 0,2 & 50 & 86 & $<0,0001$ \\
\hline$\triangle \mathrm{CRP}(\mathrm{mg} / \mathrm{l})$ & $-33,6[-132,69]$ & $-6,1[-72,18]$ & 0,3 & $-25,5[-89,6]$ & $-1[-99,58]$ & 0,04 \\
\hline Corticosteroids hip joint injections ( $n$ ) & 1 & 3 & 0,2 & 0 & 4 & 0,04 \\
\hline
\end{tabular}

